\title{
Testing for Asymmetric Pricing in the French Retail Industrial Fuel Oil Market
}

\author{
Fidelia N. Onuigbo $^{1}$ Jonathan E. Ogbuabor ${ }^{2 *}$ \\ 1.Department of Economics, Enugu State University of Science and Technology (ESUT), Enugu, Nigeria \\ 2.Department of Economics, University of Nigeria, Nsukka, Nigeria
}

\begin{abstract}
This study investigated the French industrial fuel oil market for evidence of asymmetric price adjustment and rentseeking following changes in crude oil prices. The study adopted the nonlinear autoregressive distributed lag (NARDL) framework recently advanced for modeling cointegrating relationships. The study also used monthly time series data for the period January 2005 to December 2015. The results indicate that French industrial fuel oil market is fraught with sluggish speed of adjustment, which is typical of markets witnessing uncompetitive pricing and other irregular behaviours by retail firms. The results further indicate that French industrial fuel oil market is bedeviled by the problem of short-run asymmetric price transmission from crude oil market, which is consistent with the rockets and feathers effect. However, the results did not show any evidence of rent-seeking since the observed short-run asymmetry is not obscured at pump. The study concludes that in view of the prevailing problem of rockets and feathers effect, policies that encourage continuous monitoring of the market in order to preserve competition and the overall social welfare should be embraced by policymakers and regulators in this market.

Keywords: Rockets and Feathers effect; Rent-seeking; Asymmetric Price Adjustment; Nonlinear ARDL model; France
\end{abstract}

JEL Codes: Q43; D40; C22; N94.

DOI: $10.7176 / \mathrm{JETP} / 9-2-03$

\section{Introduction}

France is a European country with negligible domestic oil production activity. As of 2012, its oil import dependency ratio stood at $98.5 \%$. This shows that France is an oil-deficient economy. Thus, it has high risk of oil supply disruption given its relatively high oil import dependency ratio. In other words, consumers of various petroleum products such as industrial fuel oil, gasoline, automotive diesel, and home heating oil are somewhat prone to the fluctuations in international crude oil market. Given that crude oil is the main input material in the production of industrial fuel oil and other petroleum products, it will be interesting to see how the French retail industrial fuel oil market responds to changes in crude oil costs. Economically, it is expected that retail prices of industrial fuel oil in France will move in tandem with the crude oil market so that econometrically the relationship can be called symmetric. However, the ongoing concern that the petroleum downstream sectors may be responding asymmetrically to changes in crude oil costs, especially following the tumbling in oil prices which started in 2013, means that the theoretical symmetric relationship may not be the case in French industrial fuel oil market.

Let us consider the records from the Monthly Oil Price Statistics of International Energy Agency (IEA) (http://www.iea.org/statistics/topics/prcesandtaxes), which monitors retail prices of petroleum products and the costs of imported crude oil in a group of eight industrialized countries, including France. This statistics indicate that while the average cost of imported crude oil in France declined from 102.56 US dollars per barrel in August 2014 to 96.08 US dollar per barrel in September 2014, the retail pump price of industrial fuel oil increased from 523.23 Euro per metric ton to 532.90 Euro per metric ton. This is an asymmetric pattern of price transmission from crude oil market to industrial fuel oil, suggesting that the retail price in this market may be stickier downwards than upwards in response to changes in crude oil costs. Indeed, such asymmetric pattern of retail price adjustment has become a major feature of the retail global energy sector. For instance, in the UK, the concern that the gasoline market may have been witnessing non-competitive pricing and collusive behavior (as a result of such asymmetric pattern of pricing) was the subject of three main investigations by the Monopolies and Mergers Commission (MMC) between1965 and 1990 (MMC, 1965, 1979, 1990). The MMC concluded that there was evidence of asymmetric response of gasoline price to changes in crude oil cost. Specifically, the MMC explained that when faced with rising input costs, sellers rapidly adjust prices upwards; but when they are faced with decreasing costs, they adjust prices downwards very sluggishly. The MMC termed this pattern of asymmetric adjustment 'rockets and feathers'. The concern in this paper is that the industrial fuel oil market in France may be witnessing similar asymmetric pattern of adjustment to crude oil price shocks. The objective of this study is therefore to examine the French retail industrial fuel oil market for evidences of asymmetric price adjustment and rent-seeking following changes in crude oil costs.

\section{An overview of the empirical literature}

Several empirical studies have investigated the problem of asymmetric transmission of changes in crude oil costs 
to retail energy markets following the initial enquiries by the UK MMC. Though MMC failed to establish its findings through econometric work, Bacon (1991) developed a quadratic quantity adjustment model for testing the rockets and feathers hypothesis put forward by the MMC using data from the UK retail gasoline market. Bacon econometrically established the reality of asymmetric price transmission from crude oil market to retail gasoline market as well as the prevalence of the rockets and feathers effect in the UK retail gasoline market. Using data for the period 1986 - 1992 and Error Correction Models, Borenstein Cameron and Gilbert (1997, henceforth BCG) investigated the US retail gasoline market using data for the period 1986 to 1992 to analyze price transmission at different points in the distribution chain. The results show that retail gasoline prices respond more quickly to increases than to decreases in crude oil prices.

Greenwood-Nimmo and Shin (2013, henceforth GS13) used the nonlinear ARDL framework to examine the UK gasoline, diesel, kerosene and gas oil markets over the period January 1999 to March 2013. They found evidence in support of the presumed asymmetry, which is largely obscured at pump where prices include both tax and duty suggesting the possibility of firms using tax system to conceal rent-seeking behavior. Chou, Chang and $\mathrm{Hu}$ (2013) estimated retail price adjustments in the gasoline and diesel markets of Taiwan, Japan, South Korea, and Singapore using monthly data between January 2004 and June 2012. The study employed an asymmetric error correction model (ECM). The results indicate that asymmetric adjustments in retail gasoline and diesel prices are common, and that the adjustments are a type of politico-economic asymmetry. Chen, Haung and Ma (2017) examined whether China's gasoline and diesel prices adjust asymmetrically to international crude oil price changes. Using monthly data on wholesale prices of gasoline and diesel products in China, and international crude oil prices from February 2006 to October 2013, they applied an asymmetric error-correction model (AECM). The findings suggest that increases and decreases in international oil prices have asymmetric effects on both wholesale prices of gasoline and diesel fuel in China, and that both increases and decreases in international oil prices have a greater effect on diesel prices than on gasoline prices in China.

Patlanakooha and Pornchaiwisetgul (2015) investigated asymmetric price transmission (APT) of gasoline price and diesel price and their causes in Thailand. Monthly data of Western Texas Instrument crude oil price, unleaded gasoline (ULG) price and high speed diesel (HSD) price, the oil fund, the stock of ULG and HSD inventories were used. The results show that APT exists for ULG but not for HSD. The oil fund does not influence the price asymmetry. Whether the oil fund is levied or otherwise, the price asymmetry is always present for ULG but not for HSD. Venditti (2010) noted that in the past decade, changes in oil prices have played a significant role in shaping inflation dynamics in the US and in the euro area, largely through their direct effect on fuel prices thereby reviving the controversy over whether the prices of petroleum products respond more promptly to positive than to negative oil price shocks. The study provides evidence on this issue for the US, the euro area and the four largest euro area countries (Germany, France, Italy and Spain), both for petrol and diesel prices. The empirical analysis shows that fuels prices respond very promptly to oil price shocks, with some heterogeneity across countries, and that no systematic evidence of asymmetries emerges.

Atil, Lahiani and Nguyen (2014) studies gasoline and natural gas markets. They used the recently developed nonlinear autoregressive distributed lag (NARDL) model to examine the pass through of crude oil prices into gasoline and natural gas prices. The short and long-run nonlinearities through positive and negative partial sum decompositions of the predetermined explanatory variables were tested using this approach. The method also offers the possibility to quantify the respective responses of gasoline oil price shocks from the asymmetric dynamic multipliers. The results show that oil prices affect gasoline prices and natural gas prices in an asymmetric and nonlinear manner, but the price transmission mechanism is not the same. Polemis and Fotis (2015) examined the asymmetric adjustment speed of gasoline price in twelve European Union (EU) countries transmitted directly in a single stage formulation using the Dynamic Ordinary Least Square (DOLS) framework. The results show strong evidence suggesting the validity of the rockets and feathers hypothesis in five out of the twelve EU countries. The findings indicates that in these countries, consumers are somewhat insulated from fluctuations in the crude oil market leaving no room for long-run rent-seeking behavior. Similarly, the null hypothesis of short-run asymmetries could not be rejected in all of the sample countries, suggesting the existence of symmetric adjustment speeds in the short-run. The study concluded that the oligopolistic structure of the local gasoline markets along with crude oil price volatility triggers the price asymmetric adjustment path. This study is consistent with Greenwood-Nimmo and Shin (2013), and sheds more light on how the manipulation of the tax system by retailers can be used to obscure asymmetry at the pump.

Polemis and Fotis (2014) explored the degree of competition in various gasoline markets and inferred possible causes of price asymmetry across the globe. The study used the Dynamic Ordinary Least Square method in order to estimate price asymmetry in twelve European countries and the United States for a sample of weekly observations which spans the period from June 1996 to August 2011. The results indicate the common perception that less competitive gasoline markets exhibit price asymmetry, while highly competitive gasoline markets follow a symmetric price adjustment path. In addition, the inclusion of taxes (VAT and excise tax) into retail gasoline prices, supports the existence of price asymmetry in many European countries. 
Clerides (2010) uses data from 2000 to 2010 for several European Union (EU) countries to investigate the response of retail gasoline and diesel prices to changes in the world oil price. The empirical findings indicate significant variation in the adjustment mechanism across countries. Kristoufek and Lunackova (2015) used weekly data between 1996 to 2014 to study gasoline price adjustments in Belguim, France Germany, Italy, Nertherlands, UK, and the USA. Using error correction model ECM, the study found no evidence of price asymmetries. Perdiguero-Garcia (2010) provides a comprehensive compilation of empirical studies on gasoline market asymmetries for 48 countries in the global economy. They observed that the analysis of price asymmetries in the gasoline market is one of the most studied in the energy economics literature.

Bagnai and Ospina (2016) studies the asymmetries in gasoline pricing using a sample of monthly data from twelve Eurozone countries running from January 1994 to December 2014. They applied nonlinear autoregressive distributed lag (NARDL) modeling framework. The results showed that while the effects of exchange rate variations display a positive asymmetry (i.e devaluation have a greater impact with respect to revaluation), crude oil price variations induce negative asymmetry (i.e. reductions in the price of crude oil have greater impact than price rises). Again, the positive asymmetry to exchange rate change is much stronger in core Eurozone countries. Wlazlowski (2003) examines the relationship between crude oil prices, the dollar-pound exchange rate and petrol prices in the UK over the period 1982-2001. The study used quantitative methods to examine the existence of long-run equilibrium and test for the presence of asymmetric patterns in the short-run responses to upstream price changes. The degree of asymmetry in the adjustment towards long-run equilibrium was also examined. The results confirm that short-run response is greater for increases in upstream prices and that the long-run equilibrium is reached faster after increase in upstream prices. Thus, the opinion held by drivers in the UK, which is the prevalence of the rockets and feathers effect, is confirmed.

da Silva et al. (2014) analyzed the existence of asymmetric transmission of prices in the Brazilian gasoline market following a regional approach, using a disaggregated data set for the period between May 2004 and February 2011. The main result finds evidence of symmetric price transmission in retail gasoline market due to price shocks arising from the distributors. However, the study stressed that all observed asymmetries following the disaggregation of the data indicate that the asymmetries do not constitute a national problem, but specific to each city and different for each of the regions in Brazil. This study suggests that interesting empirical evidences can be obtained by using disaggregated data in the study of asymmetric price adjustments in retail energy markets. Valadkhani (2013) examines if the long-run relationship between retail and wholesale petrol prices is subject to adjustment asymmetric behaviour using weekly Australian data across 111 locations over the period 2007-2012. The study specified a short-run dynamic model in which three feedback coefficients capture three different types of disequilibria: large and positive; large and negative; small positive/negative. Significant evidence of asymmetric behaviour is found in 28 locations, which are mainly in Tasmania, Queensland and New South Wales. In these locations, when prices are conspicuously above the equilibrium path, retailers sluggishly lower their prices but when prices are substantially below the equilibrium values, the adjustment speed is significantly faster.

Bastianin, Galeotti and Manera (2014) observed that even though there have been many contributions documenting that downstream prices are more reactive to increases than to decreases in upstream prices, little is known about the forecasting performance of econometric models incorporating asymmetric price transmission from crude oil to gasoline. The study filled this gap by comparing point, sign and probability forecasts from a variety of Asymmetric-ECM (A-ECM) and Threshold Autoregressive ECM (TAR-ECM) specifications against a standard ECM. Forecasts from A-ECM and TAR-ECM subsume the rockets and feathers hypothesis (RFH), while the ECM implies symmetric price transmission from crude oil to gasoline. The study quantify the forecast accuracy gains due to incorporating the RFH in predictive models for the prices of gasoline and diesel, and show that the RFH is useless for point forecasting, while it can be exploited to produce more accurate sign and probability forecasts. It also highlighted that the forecasting performance of the estimated models is time-varying.

Bachmeier and Griffin (2003) used daily data for 1985 - 1998 for the U.S. gasoline market. They also used the standard Engle-Granger two-step estimation procedure as well as the BCG's nonstandard specification, and found no evidence of asymmetry in the U.S. wholesale gasoline prices. Bachmeier and Griffin (2003) investigated the sources of the difference in their result and that of BCG. Their findings indicate that the sources of the difference are twofold. First, they use the standard Engle-Granger two-step estimation procedure, whereas BCG used a nonstandard estimation methodology. Second, even using BCG's nonstandard specification, the use of daily rather than weekly data yields little evidence of price asymmetry.

Honarvar (2009) used Crouching ECM approach to investigate the U.S. retail gasoline market. The results are consistent with Bachmeier and Griffin (2003), which found that there is no evidence of rockets and feathers effect in the U.S. gasoline market. Bettendorf, Van Der Geest and Varkevisser (2003) analyses retail price adjustments in the Dutch gasoline market by estimating an asymmetric error correction model on weekly price changes for the years 1996 to 2001. They constructed five datasets, one for each working day. The conclusions on asymmetric pricing are shown to differ over these datasets, suggesting that the choice of the day for which prices are observed matters more than commonly believed. The study therefore concluded that the insufficient robustness 
of outcomes might explain the mixed conclusions found in the literature; and using two approaches, the study showed that the effect of asymmetry on Dutch consumer costs is negligible.

The above overview of the empirical literature shows that the extant literature is disproportionately skewed in favour of the road fuel markets, that is, the gasoline and automotive diesel markets. Most of the studies did not focus on the industrial fuel oil market. The above review also shows that while some studies found evidence in support of the hypothesized asymmetry, others did not find such evidence. Hence, this paper contributes to the ongoing investigations on asymmetric price transmission of changes in crude oil costs to retail energy products with particular emphasis on French industrial fuel oil market. Specifically, this study investigates the French industrial fuel oil market for evidence of sluggish speed of adjustment, rockets and feathers effect, and the possibility of rent-seeking behavior by retail firms.

\section{Data and methodology}

The data for this study consists of monthly time series observations for the period January 2005 to December 2015 , a total of 132 observations. The variables of interest are the retail prices of industrial fuel oil and the costs of imported crude oil in France. The retail prices are available not only at pump (i.e inclusive of tax and duty) but also exclusive of tax and duty (i.e ex-tax prices). The data were sourced from the International Energy Agency (IEA) monthly oil price statistics. To effectively track the asymmetry in the response of the retail price of industrial fuel oil to change in the cost of crude oil, this study used the crude oil cost for France measured in dollars per barrel. However, the retail price of industrial fuel oil that is measured in the national currency of France was converted to U.S dollars using the exchange rate data obtained from OECD statistics (monthly Monetary and Financial Statistics, MEI). The entire dataset was indexed to year 2010 (i.e. $2010 \mathrm{Y}=100 \%$ ). Thereafter, the data was logged prior to estimation. Figure 1 plots the data using its indexed representation. This figure indicates that the prices track themselves closely, thereby suggesting that the relationship between them might be symmetric rather than asymmetric. The plots also suggest that a stable equilibrium relationship may be existing between the prices. This study will investigate this relationship as part of the empirical analysis.

Figure 1: Time series plot of the data

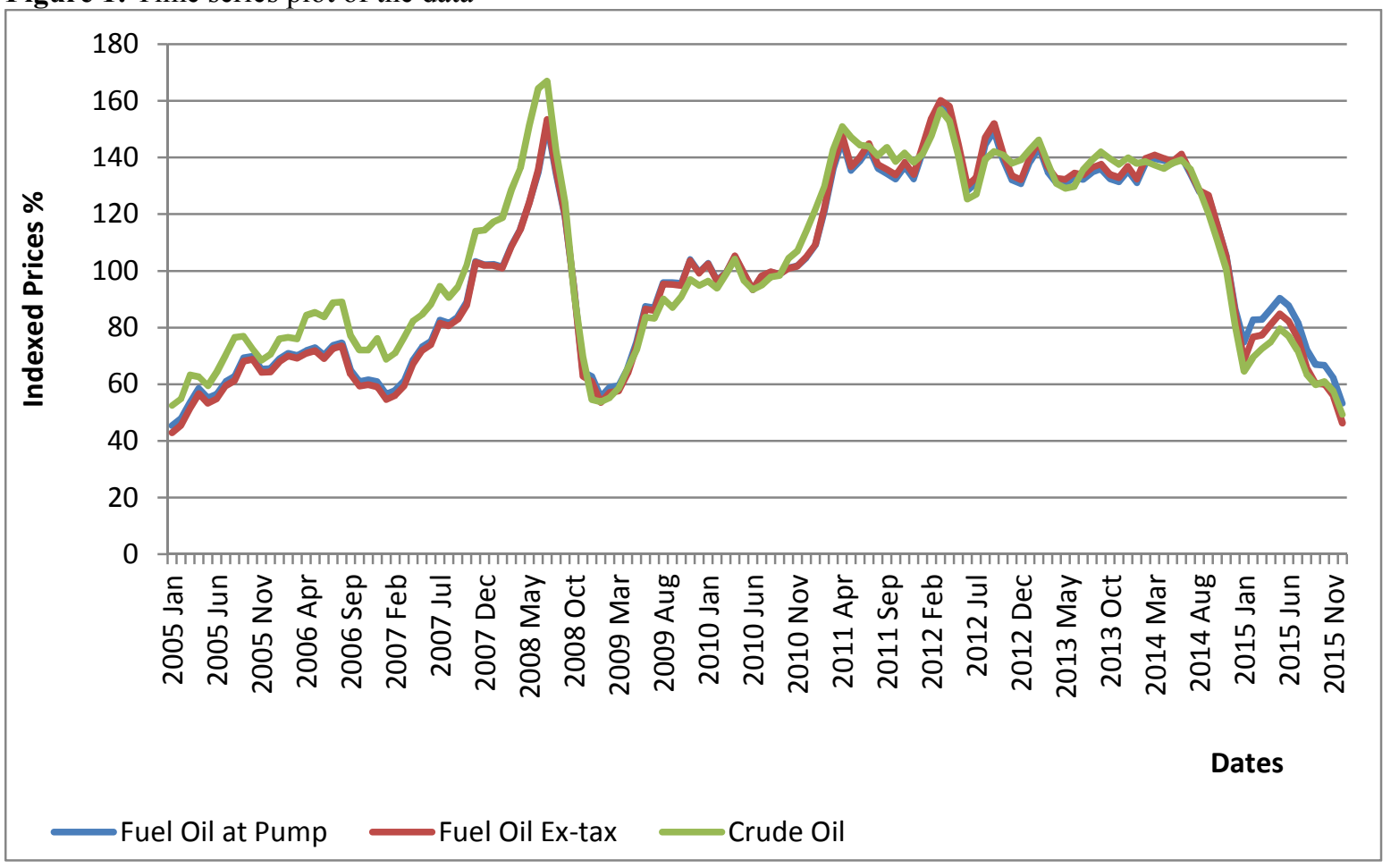

Source: Authors. Note: Fuel oil at pump includes tax and duty, while fuel oil ex-tax is exclusive of tax and duty. The plots are based on the indexed representation of the data before they were logged for estimation.

This study adopted the econometric framework applied by GS13 in modeling the asymmetric price transmission in the UK retail energy sector, which was initially advanced by Shin, Yu and Greenwood-Nimmo (2013) for modeling asymmetric cointegration and dynamic multipliers in a non-linear autoregressive distributed lag (NARDL) framework. Under this framework, short-run and long-run non-linearities were introduced through positive and negative partial sum decompositions of the explanatory variables. In the empirical literature, Webber (2000), Lee (2000), Viren (2001), Bachmeier and Griffin (2003), and BCG, among others, applied partial sum decompositions to the analysis of dynamic asymmetry with great success. The NARDL framework is built around 
the asymmetric cointegrating relationship of the form:

$$
Y_{t}=\theta^{+} X_{t}^{+}+\theta^{-} X^{-}+u_{t}
$$

Where $Y_{t}$ is an I(1) variable, and the explanatory variable is decomposed as follows:-

$X_{t}=X_{0}+X_{t}^{+}+X_{t}^{-}$

Where $X_{t}^{+}=\sum_{j=1}^{t} \max \left(\Delta \mathrm{X}_{\mathrm{j}}, 0\right)$ and $X_{t}^{-}=\sum_{j=1}^{t} \min \left(\Delta \mathrm{X}_{\mathrm{j}}, 0\right)$ are partial sum processes of positive

and negative changes in $X_{t}$, while $X_{0}$ is an initial threshold value that is assumed to be zero following Shin, $\mathrm{Yu}$ and Greenwood-Nimmo (2013). $\Delta$ is the first difference operator while $\theta^{+}$and $\theta^{-}$are the associated asymmetric long-run parameters. The $\operatorname{NARDL}(p, q)$ model associated with equation (1) can be written in its level form as follows:

$$
Y_{t}=\sum_{j=1}^{P} \phi_{\mathrm{j}} \mathrm{Y}_{\mathrm{t}-\mathrm{j}}+\sum_{j=O}^{q}\left(\theta_{\mathrm{j}}^{+} X_{t-j}^{+}+\theta_{j}^{-} X_{t-j}^{-}\right)+\varepsilon_{\mathrm{t}}
$$

The underlying model in this study is derived from equation (3) following Shin, Yu and Greenwood-Nimmo (2013). This is specified in its error correction form as follows:

$$
\begin{aligned}
& \Delta \mathrm{Y}_{\mathrm{t}}=\rho \mathrm{Y}_{\mathrm{t}-1}+\theta^{+} X_{t-1}^{+}+\theta^{-} X_{t-1}^{-}+\sum_{j=1}^{p-1} \phi_{\mathrm{j}} \Delta \mathrm{Y}_{\mathrm{t}-\mathrm{j}}+\sum_{j=O}^{q-1} \quad\left(\pi_{\mathrm{j}}^{+} \Delta \mathrm{X}_{\mathrm{t}-\mathrm{j}}^{+}+\pi_{\mathrm{j}}^{-} \Delta \mathrm{X}_{\mathrm{t}-\mathrm{j}}^{-+}\right) \\
& +\varepsilon_{\mathrm{t}}
\end{aligned}
$$

Where $\rho$ is the speed of adjustment while $\beta^{+}=\frac{-\theta^{+}}{\rho}$ and $\beta^{-}=\frac{-\theta^{-}}{\rho}$ are the asymmetric long-run parameters.

In the above specifications, $Y_{t}$ captures the retail price of industrial fuel oil in France, while $X_{t}$ captures the crude oil costs for France. To ascertain the orders of integration of the variables in this study, the ADF unit root tests were used. This is to ensure that they are consistent with the underlying requirements of the nonlinear ARDL framework. The result of cointegration tests based on the bounds testing approach of Pesaran, Smith and Shin 2001 (henceforth PSS) and the t-BDM statistic of Banerjee et al (1998) are also reported in this study.

\section{Empirical results and discussion}

We began this empirical analysis by examining the time series properties of the data. To do this, we performed the ADF unit root test on all the variables. The results are reported in Table 1 . The results indicate that all the variables are integrated of order one, I(1), which is consistent with the underlying assumptions of our model. These results suggest that the variables may be cointegrated. Thus, we include cointegration analysis as part of the nonlinear ARDL estimation results based on the bounds testing procedure of PSS and the t-BDM statistic of Banerjee et al (1998).

Table 1: ADF Unit root test results

\begin{tabular}{|l|l|l|l|l|}
\hline Variables & $\begin{array}{l}\text { Test 5\% Critical } \\
\text { Values }\end{array}$ & $\begin{array}{l}\text { Level } \\
\text { ADF Test Stat }\end{array}$ & $\begin{array}{l}\mathbf{1}^{\text {st }} \text { Difference } \\
\text { ADF Test Stat }\end{array}$ & $\begin{array}{l}\text { Order of } \\
\text { Integration }\end{array}$ \\
\hline Fuel Oil at Pump & -3.445 & -1.352 & $-7.152^{*}$ & $\mathrm{I}(1)$ \\
\hline Fuel Oil Ex-tax & -3.445 & -1.102 & $-7.195^{*}$ & $\mathrm{I}(1)$ \\
\hline Crude Oil & -3.445 & -1.833 & $-5.919^{*}$ & $\mathrm{I}(1)$ \\
\hline
\end{tabular}

Source: Authors. Notes: Fuel oil at pump denotes the retail prices that are inclusive of tax and duty; while fuel oil ex-tax is the ex-tax price. * denotes significance at 5\% level.

The NARDL estimation results for this study based on equation (4) are reported in Table 2 . We find that the speed of adjustment is quite sluggish for both the ex-tax prices and the pump prices with values of $20 \%$ and $26 \%$, respectively. Both speed of adjustment are highly statistically significant, even at the $1 \%$ level. GreenwoodNimmo and Shin (2013) also found similar pattern of sluggish speed of adjustment in the UK retail petroleum products markets. Such sluggish speed of adjustment is usually associated with irregular behaviours such as weak competition and prolonged periods of mispricing. This finding raises serious anti-trust and consumer welfare issues that should not be ignored by policy makers in this economy. These results are also consistent with the dynamics of the French retail industrial fuel oil and the country's profile provided by the IEA Energy Supply Security 2014. The IEA statistics indicate that France has negligible domestic oil production activity. Its oil import dependency ratio was $98.5 \%$ as of 2012 . The high rate of oil consumption by the industrial sector in this economy is also consistent with the observed sluggish speed of adjustment.

The results also show that there is significant evidence of long-run asymmetry at the $1 \%$ level in both ex-tax and pump prices. The pattern of this long-run asymmetry indicates that the both retail prices respond more strongly to positive (i.e. increases) than to negative (decreases) changes in crude oil costs since the values for $\beta^{+}$(which are 
1.13 and 1.00 for ex-tax and pump prices, respectively) are higher than the corresponding values for $\beta^{-}$(which are 1.07 and 0.92 , respectively). However, these estimated coefficients which ranges between $0.92-1.13$ are quite high (i.e. close to unity), indicating that consumers in this market are somewhat insulated to the fluctuations in the international crude oil market. Overall, we find at this point that in the long-run, retail industrial fuel oil price in France is stickier downwards than upwards in its response to crude oil cost shocks. In what follows, we consider if these findings are robust in the short-run.

The results indicate significant evidence of short-run additive asymmetry both for the ex-tax prices and the pump prices at the $1 \%$ level. The results indicate that crude oil price increases are passed through more strongly and rapidly than price decreases in the periods immediately following the shocks. This is because the sums of the estimated positive short-run parameters (which are 1.22 and 1.19 for ex-tax and pump prices, respectively) are higher than the corresponding sums of the negative short-run parameters (which are 0.62 and 0.56 , respectively). Indeed, these results provide clear evidence of the prevalence of the rockets and feathers effect in the French retail industrial fuel oil market. Thus, our results have now shown that both in the long-run and short-run, retail industrial fuel oil price in France is stickier downwards than upwards while responding to crude oil cost shocks. However, we do not find evidence of rent-seeking in this market since the observed short-run asymmetry is not obscured at pump. These findings are consistent with the dynamics of the French oil industry earlier highlighted in this report. For instance, the fact that France is an oil-deficient economy with high oil import dependency ratio predisposes its downstream sector to irregular behaviours such as mispricing and collusion. Our results therefore indicate that there is need for adequate regulation and supervision of the market to forestall these failures.

The diagnostic checks indicate that the assumptions of the underlying model have been adequately satisfied. There exists stable long-run or equilibrium relationship between the variables at $5 \%$ level as shown by both the bounds testing approach of Pesaran, Smith and Shin (2001) (PSS for short) and the t-BDM statistic of Banerjee et al (1998). There is no evidence of autocorrelation or hetroscedastiticity problem in the results at the 5\% level. The adjusted $\mathrm{R}^{2}$ which indicated the value of $84 \%$ in both models shows that changes in crude oil cost shocks account substantially for variations in the industrial fuel oil market, which is consistent with economic expectation.

Table 2: NARDL estimation results

\begin{tabular}{|l|l|l|}
\hline & Fuel Oil Ex-tax & Fuel Oil at Pump \\
\hline Estimated Coefficients & & \\
\hline$\rho$ & $-0.20^{* * *}$ & $-0.26^{* * *}$ \\
\hline$\beta^{+}$ & $1.13^{* * *}$ & $1.00^{* * *}$ \\
\hline$\sum_{j=1}^{q-1} \pi_{j}^{+}$ & $1.07^{* * *}$ & $0.92^{* * *}$ \\
\hline$\sum_{j=1}^{q-1} \pi_{j}^{-}$ & & $1.19^{* * *}$ \\
\hline Symmetry Tests & $1.22^{* * *}$ & \\
\hline $\mathcal{H}_{0}: \beta^{+}=\beta^{-}$ & $0.62^{* * *}$ & $0.56^{* * *}$ \\
\hline $\mathcal{H}_{0}: \sum_{j=1}^{q-1} \pi_{j}^{+}=\sum_{j=1}^{q-1} \pi_{j}^{-}$ & $12.42^{* * *}$ & \\
\hline Diagnostics & & $42.91^{* * *}$ \\
\hline $\mathrm{F}_{\mathrm{PSS}}$ & $6.80^{* * *}$ & \\
\hline $\mathrm{t}_{\mathrm{BDM}}$ & & $8.71^{* * *}$ \\
\hline $\mathrm{BG}$ Test $\left(\mathrm{NR}^{2}\right)$ & $4.99^{*}$ & \\
\hline ARCH Test & $-3.44^{* *}$ & $6.50^{* *}$ \\
\hline$\overline{\mathcal{R}}^{2}$ & 14.13 & $-4.20^{* * *}$ \\
\hline
\end{tabular}

Source: Authors. Notes: The notation for the estimated coefficients relates to the NARDL model of equation (4). The reported symmetry tests are standard Wald tests. The BG Test is the Breusch-Godfrey serial correlation test, while the ARCH Test is the standard Heteroskedasticity Test. The BG Test and the ARCH Test were conducted at lag 12 , since the dataset comprises monthly series. The relevant $\mathrm{k}=1$ critical values reported by PSS for the $\mathrm{t}_{\mathrm{BDM}}$ statistic are $-2.91,-3.22$, and -3.82 at the $10 \%, 5 \%$ and $1 \%$ levels. The equivalent critical values for the $\mathrm{F}_{\mathrm{PSS}}$ statistic are 4.78, 5.73 and 7.84. * denotes Significance at the $10 \%$ level; ** denotes Significance at the $5 \%$ level; $* * *$ denotes Significance at the $1 \%$ level.

\section{Conclusion and policy implications}

This paper examined the French industrial fuel oil market for evidence of asymmetric price adjustment and rentseeking following changes in crude oil prices. The study used the nonlinear autoregressive distributed lag (NARDL) modeling framework and monthly time series data for the period January 2005 to December 2015. The results 
indicate that French industrial fuel oil market is fraught with sluggish speed of adjustment, which is typical of markets witnessing uncompetitive pricing and other irregular behaviours by retail firms. The results further indicate that French industrial fuel oil market is bedeviled by the problem of short-run asymmetric price transmission from crude oil market, which is consistent with the rockets and feathers effect. However, the results did not show any evidence of rent-seeking since the observed short-run asymmetry is not obscured at pump. In view of the prevailing problem of rockets and feathers effect, the paper supports policies that will encourage continuous monitoring of the market in order to preserve competition and the overall social welfare.

\section{References}

Atil, A., Lahiani, A. and D. K. Nguyen (2014). Asymmetric and nonlinear pass-through of crude oil prices to gasoline and natural gas prices. Energy Policy, 65(C), 567-573.

Bachmeier, L. J. and J. M. Griffin (2003). New Evidence on Asymmetric Gasoline Price Responses. The Review of Economics and Statistics 85(3), 772-776.

Bacon, R.W. (1991). Rockets and Feathers: The Asymmetric Speed of Adjustment of UK Retail Gasoline Prices to Cost Changes. Energy Economics 13, 211-218.

Bagnai, A. and C. A. M. Ospina (2016). Price asymmetries in the European gasoline market. Working Papers Series 1602, Italian Association for the Study of Economic Asymmetries, Rome (Italy).

Banerjee, A., Dolado, J. and R. Mestre (1998). Error-correction Mechanism Tests for Cointegration in a Singleequation Framework. J. Time Ser. Anal. 19, 267-283.

Bastianin, A., Galeotti, M. and M. Manera (2014). Forecasting the oil-gasoline price relationship: should we care about the Rockets and the Feathers? Working Papers 269, University of Milano-Bicocca, Department of Economics.

Bettendorf, L., Van Der Geest, S. A. and M. Varkevisser (2003). Price Asymmetries in the Dutch Retail Gasoline Market. Energy Economics 25, 669-689.

Borenstein, S., Cameron, A.C. and R. Gilbert (1997). Do Gasoline Prices Respond Asymmetrically to Crude Oil Prices? Quarterly Journal of Economics 112, 305-339.

Chen, Y., Huang, G. and L. Ma (2017). Rockets and feathers: The asymmetric effect between China's refined oil prices and international crude oil prices. Sustainability 9, 381 - 399. doi:10.3390/su9030381.

Chou, K., Chang, C. and F. Hu (2013). An Empirical Study of Asymmetric Pricing in Retail Gasoline and Diesel Markets in Taiwan, Japan, South Korea, and Singapore. International Journal of Financial Research 4(3), $35-42$.

Clerides, S. (2010). Retail fuel price response to oil price shocks in EU countries. Cyprus Economic Policy Review, 4(1), 25-45

da Silva, A. S., Vasconcelos, C. R. F., Vasconcelos, S. P., and R. S. de Mattos (2014). Symmetric transmission of prices in the retail gasoline market in Brazil. Energy Economics, 43(C), 11-21.

Greenwood-Nimmo, M. and Y. Shin (2013). Taxation and the Asymmetric Adjustment of Selected Retail Energy Prices in the UK. Economics Letters 121, 411-416.

Honarvar, A. (2009). Asymmetry in Retail Gasoline and Crude Oil Price Movements in the United States: An Application of Hidden Cointegration Technique. Energy Economics 31(3), 395-402.

Kristoufek, L. and P. Lunackova (2015). Rockets and feathers meet Joseph: Reinvestigating the oil-gasoline asymmetry on the international markets. Energy Economics 49, 1 - 8 .

Lee, J. (2000). The Robustness of Okun's Law: Evidence from OECD Countries. Journal of Macroeconomics 22, 331-56.

Monopolies and Mergers Commission (MMC) (1965). Report on the Supply of Petrol to Retailers in the United Kingdom, HMSO, London.

Monopolies and Mergers Commission (MMC) (1979). Report on the Supply of Petrol in the United Kingdom by Wholesale, HMSO, London.

Monopolies and Mergers Commission (MMC) (1990). The Supply of Petrol, HMSO, London.

Pattanakooha, P. and P. Pornchaiwisetgul (2015). The Effect of Stock, Government Policy, and Monopoly on Asymmetric Price Transmission in Thailand. International Journal of Energy Economics and Policy, 5(4), 926-933.

Perdiguero-Garcia, J. (2010). Symmetric or Asymmetric Gasoline Prices? A Metaanalysis Approach. Working Paper 2010/13, Research Institute of Applied Economics, Universitat de Barcelona. Accessed January 18, 2016 (www.ub.edu/irea/).

Pesaran, M.H., Smith, R.J. and Y. Shin (2001). Bounds Testing Approaches to the Analysis of Level Relationships. Journal of Applied Econometrics 16, 289-326.

Polemis, M. L. and P. N. Fotis (2014). The taxation effect on gasoline price asymmetry nexus: Evidence from both sides of the Atlantic. Energy Policy 73, 225 - 233.

Polemis, M. L. and P. N. Fotis (2015). Rent seeking oligopolistic behaviour in European gasoline markets. 
Economics Bulletin 35(1), $827-833$.

Shin, Y., Yu, B. and M. J. Greenwood-Nimmo (2013). Modelling Asymmetric Cointegration and Dynamic Multipliers in a Nonlinear ARDL framework, in: Horrace, W. C. and Sickles, R. C., eds., Festschrift in Honor of Peter Schmidt: Econometric Methods and Applications, Springer Science \& Business Media, New York.

Valadkhani, A. (2013). Do petrol prices rise faster than they fall when the market shows significant disequilibria? Energy Economics 39, 66-80.

Venditti, F. (2010). Down the non-linear road from oil to consumer energy prices: no much asymmetry along the way. Temi di discussion (Economic working papers) 751, Bank of Italy, Economic Research and International Relations Area.

Viren, M. (2001). The Okun Curve is Non-linear. Economics Letters 70, 253-57.

Webber, A.G. (2000). Newton's Gravity Law and Import Prices in the Asia Pacific. Japan and the World Economy 12, 71-87.

Wlazlowski, S. (2003). Petrol and Crude Oil Prices: Asymmetric Price Transmission. Ekonomia 11, 1-25. 